ON THE SOLUTION OF

GENERAL EQUIIIBRIUM MODELS

Larry J. Kimbel1

Graduate School of Management

University of California, Los Angeles

Glenn W. Harrison

Department of Economics

University of Western Australia

Discussion Paper 82.05

April 1982 


\title{
ON THE SOLUTION OF GENERAL EQUILIBRIUM MODELS
}

\author{
by \\ Larry J. Kimbell \\ and \\ Glenn W. Harrison
}

Apri1 1982.

Kimbel1 is Associate Professor and Director, UClA Business Forecasting Project, Graduate School of Management, UCLA. -Harrison is Visiting Senior Research Fellow, Department of Economics, University of Western Australia. We are grateful to Glenn Graves, Edward Leamer, Charles McLure Jr., Herbert Scarf, and participants of the NBER Conference on Applied General Equilibrium Analysis (San Diego, California, 1981) and the UCLA Mathematical Economics Workshop for comments. The National Science Foundation (Grant DAR-78-26309) has provided generous research support. 


\section{CONTENTS}

\section{Section}

page

1. INTRODUCTION . . . . . . . . . . . . . . . . ......... 1

2. THE ANALYTIC FACTOR PRICE SOLUTION . . . . . . . . . . . . . . . . . 3

3. SYSTEM-WIDE SEPARABILITY ....................... . . . . .

4. THE FACTOR PRICE REVISION RULE . . . . . . . . . . . . . . . . 11

5. THE FACTOR PRICE REVISION RULE AS A GENERAL ALGORITHM . . . . . . . . . 13

Structural Form of the General Equilibrium Mode1 . . . . . . . . . . 13

A Special Case: The Aralytic Factor Price Solution . . . . . . . . . 17

Four Important Extensions . . . . . . . . . . . . . . . . . 21

Multiple Consumers . . . . . . . . . . . . . . . . . 21

Non-Uniform Elasticities of Substitution . . . . . . . . . 22

Intermediate Trade . . . . . . . . . . . . . . . 23

The Role of Government . . . . . . . . . . . . . . . 25

6. ILLUSTRATIVE APPLICATIONS . . . . . . . . . . . . . . . 28

Some Familiar Analytic Results . . . . . . . . . . . . . . 28

Tax Incidence Analysis . . . . . . . . . . . . . . . . . 28

International Trade Theory . . . . . . . . . . . . 30

Some Computational Experience . . . . . . . . . . . . . . . 33

7. CONCLUDING PERSPECTIVES . . . . . . . . . . . . . . . . . . . 36

Appendix $\quad$ page

A. A SIMPLE RECURSIVE SOLUTION . . . . . . . . . . . . . . . . . . . 39

BIBLTOGRAPHY . . . . . . . . . . . . . . . . . . . . . 41 


\section{Section 1}

\section{INTRODUCTION}

Two important and influential themes in applied general equilibrium analysis were initiated by Harberger [1962] [1966] and Scarf [1967] [1973], respectively: the use of analytic approximations to problems of differential tax inci-. dence, and the use of numerical computations of general equilibria. Each approach has well-known strengths and weaknesses relative to the other, and both continue to enjoy widespread popularity with economists ${ }^{2}$. The purpose of this paper is to present a consolidation and extension of these two approaches, in the form of two new procedures for the computation of general equilibria.

Section 2 presents our Analytic Factor Price Solution to a useful class of general equilibrium (GE) models. This Solution provides an exact, algebraic closed-form solution for the general equilibrium values of all endogenous variables (i.e., the reduced-form of our structural GE mode1). No iterations whatsoever are required to solve such GE models. Section 3 explains and rationalizes the basis for our new solution, which rests on a System-Wide Separability property of the class of GE models considered.

1 Mciure [1975] provides an excellent exposition and survey of analytic extensions and applications of the Harberger model. Scarf and Shoven [1983] collect a number of applications and extensions of the Scarf approach. A number of recent papers use the latter approach to examine policy issues familiar from the earlier Harberger literature: see Fullerton, King, Shoven and Whalley [1981], Fullerton, Henderson, and Shoven [1983], and Kimbell and Harrison [1983], for example. Shoven [1976] and Harberger and Bruce [1976] provide an interesting exchange on the relative strengths of the two basic solution approaches. 
Section 4 presents our Factor Price Revision Rule for a less restrictive class of GE models. This Rule provides a surprisingly rapid iterative solution algorithm for GE models that do not appear to have a closed-form representation. Section 5 provides a formal derivation of the Analytic Factor Price Solution as a special case of the Factor Price Revision Rule. This derivation, apart from its intrinsic importance, serves to motivate why the Factor Price Revision Rule is such a powerful iterative algorithm for more general models. Specifically, we examine four important complications of popular GE models that do not appear to allow a closed-form representation, but do not significantly diminish the ability of our Rule to find a solution by iteration.

Section 6 presents some illustrative applications of our two solution procedures. Several familiar analytic results from the Tax Incidence and International Trade literatures are examined in the light of our solution methods. The computational speed of our approach is also illustrated by means of a hypothetical example of a numerical GE model.

Section 7 provides a number of concluding perspectives on the potential applications of our results. 


\section{Section 2}

\section{THE ANALYTIC FACTOR PRICE SOLUTION}

The central thrust of our efforts to develop a faster and more accurate solution algorithm for general equilibrium models has been to sacrifice generality for closed form analytic solutions to the various sub-problems implied by a general equilibrium model. For the class of GE model considered here, the only iterative process involves the determination of equilibrium factor prices. Use of neoclassical production functions; as extended by fixed-coefficient intermediate input requirements, means that output prices are analytically determined by cost-minimization and the zero-profit assumption ${ }^{2}$.

For a class of general equilibrium models, to be specified below, the closed-form solution is given by the following Analytic Factor Price Solution:

$$
P(f)=(K(f) / K(1))^{1 / s}(X(f) / X(1))^{-1 / s}
$$

for $f=2$ to NFAC (the number of factors in the mode1), with $P(1)=1.0$ and

2 More general linear activity specifications, such as used by Scarf [1967] [1973], permit multiple outputs but also include output prices in the price vector space as additional dimensions. The linear activity approach does not have to define some goods as factors on an a priori basis, since a given good is a "factor" if it has a negative coefficient in any linear activity. We accept this restriction that factors be stipulated a priori as worth the gain in reduced dimensionality. Similarly, our way of specifying the role of government implies that the government budget constraint is imposed analytically and (unlike the approach of Fullerton, Shoven and Whalley [1978]) does not add another dimension to the search. 


$$
K(f)=\underset{g=1}{\mathrm{NCOM}} a(g)^{s-1} b(g)^{s} d(f, g)^{s} T(f, g)^{-s},
$$

and where $P(f)$ is the price of factor $f, X(f)$ is the (perfectly inelastic) aggregate supply of factor $f, s$ is the elasticity of substitution in production (uniform across all industries) and consumption, $a(g)$ is the efficiency parameter for producing good $\mathrm{g}$, NCOM is the number of produced goods (or commodities), $b(g)$ is the distribution parameter for good $g$ in the CES utility function of the (single) consumer, $d(f, g)$ is the distribution parameter of factor $f$ in the CES production function for good $g$, and $T(f, g)$ is unity plus the fractional rate of taxation on the use of factor $f$ in industry $g$. The price of the first factor is taken without loss of generality to be the numeraire.

The Analytic Factor Price Solution is known for models that are general with respect to: (i) any number of factors and goods; (ii) any pattern of distribution parameters in the single-level CES production functions or (single). utility function; (iii) any pattern of efficiency parameters in the production function; and (iv) any arbitrary pattern of factor taxes across factors and producing sectors. The exact solution does not apply to models with: (i) more than one private household; (ii) any interindustry (input-output) flows; (iii) elasticities of substitution in production that vary from sector to sector; (iv) an elasticity of substitution in consumption different from the (uniform) elasticity of substitution in production, and (v) government factor demands that are not proportional to aggregate private industry factor demands. 


\section{Section 3}

\section{SYSTEM-WIDE SEPARABILITY}

The Analytic Factor Price Solution exhibits a property that we will call System-Wide Separability, since it implies that any changes in the tax rates on (non-numeraire) factor $f$ alter only the price of factor f. Equivalently, $a$. change in the tax rates on the numeraire factor 1 change all other factor prices by exactly the same proportion. More formally ${ }^{3}$,

$$
\frac{d[P(f) / P(k)]}{\partial[T(g, j)]}=0,
$$

for $f, k$, and $j$ not equal, and for all such triples of $f, k$, and $j$. This property does not imply that the price of factor $f$ adjusts enough to capitalize fully the tax changes -- there can still be excise tax effects via changes in goods prices -- but the burden of increased taxes on one factor produce utterly no relative factor price changes among the other factors. In this Section we provide an explanation for this important and powerful property.

The Analytic Factor Price Solution leads to equations for factor intensities and output as follows:

${ }^{3}$ Proof: Notice that $T(g, j)$ is not an argument of the formula for $P(f) / P(k)$. 


$$
\begin{aligned}
& F(g, f)=\left[d(g, f)^{s} X(f)\right] /[K(f) * Z] \\
& Q(g)=b(g)^{s} * z \\
& \text { where } \quad Z=\left[\underset{f=1}{E} d(g, f)^{s} K(f)^{-r} X(f)^{I}\right] .
\end{aligned}
$$

The allocation of factor $f$ to the production of good $g, A(g, f)$, is simply the . product of the relevant factor intensity and output:

$$
\begin{aligned}
A(g, f) & =F(g, f) * Q(g) \\
\therefore & =\left[d(g, f)^{s} b(g)^{s} X(f)\right] / K(f)
\end{aligned}
$$

Suppose the endowment of factor $i$ increases, holding constant all other endowments and parameters. The ratio of the new factor allocation to the old factor allocation, for any arbitrary good $\mathrm{g}$, becomes:

$$
\begin{aligned}
& A(i, g)=X(i)^{*} / X(i) \\
& A(g, f)=1.00,
\end{aligned}
$$

for all $f$ not equal to $i$, and where

$$
X(i)^{*}=\text { new value of } X(i)
$$

For all factors other than $i$ the full allocation across all industries is completely invariant to changes in the endowment of factor $i$. Substituting for $A(g, f)$ yields the Factor Use Decomposition Formula: 


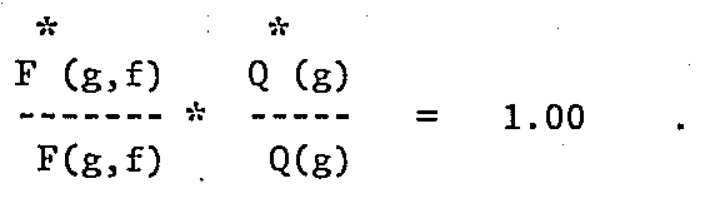

The ratio of the output of good $g$ after the expansion of the endowment of factor $i$ to the output of good $g$ before the endowment change,

$$
Q(g) / Q(g) \text {, }
$$

is called the "expansion effect". It shows the proportion by which the use of factor $f$ in producing good $g$ would increase if output changed but factor prices were constant ${ }^{4}$. The ratio of the factor intensities,

$$
F(g, f) / F(g, f)
$$

is called the "substitution effect". It shows how the demand for factor $f$ in producing good $g$ would have changed, given the factor price changes, holding output constant. The Factor Use Decomposition Formula shows that the substitution effect is identically equal to the reciprocal of the expansion effect for all factors other than the one which changed, and for each and every industry. Essentially, the special restrictions involved in our Analytic Factor Price Solution are sufficient to make the expansion effect identically offset the substitution effect, leaving allocations other than X(i) unchanged ${ }^{5}$.

4 Recall that the class of production functions currently being considered are homothetic and have constant returns to scale.

5 Note that this result is analogous to the familiar result that in the case of Cobb-Douglas production functions cross-price elasticities of factor demand are identically zero, even though they are not zero for the more general CES case. 
This result also helps to explain a distinctive feature of the Analytic Factor Price Solution -- the System-Wide Separability property. The CES family of production functions is strongly separable; i.e., the marginal rate of substitution between factors $f$ and $j$ is invariant to changes in any other factor $i$, holding the inputs of $f$ and $j$ constant. An increase in the endowment of factor $i$, since it does not alter the amounts of $f$ and $j$ used in any production function (in a general equilibrium), leaves unchanged these marginal rates of substitution. The ratio of factor prices $f$ and $j$ is therefore invariant to changes in the endowment of factor $i$. System-Wide Separability is therefore simply the result of strong separability of CES production functions, combined with the special result that allocations of factors other than $i$ are invariant to changes in the endowment of factor $i$.

Figure 1 illustrates the results just discussed for the two-good two-factor case. Assume the endowment of capital doubles, holding constant the endowment of labour and other parameters. The output of both goods will commonly expand since the production possibility frontier shifts outward for both goods. If factor prices did not change, the demand for labour would rise in both industries. The relative factor price of labour must rise, of course, until the aggregate demand equals the (unchanged and inelastic) labour endowment. There could be higher demand in one industry offset by lower demand in the other industry. However, the special restrictions of our model imply that the demand for labour is unchanged in each industry.

Notice in Figure 1 that doubling the amount of capital increases the output of both goods with a relatively larger percentage increase in the output of good 2, which is relatively intensive in capital. The amounts of capital demanded double in both industries and the amount of labour demanded is the same in both industries. 
- 01-02 Produation Poesibilitiae

Q1 1.5 Bafore After Copitel Inoreane.

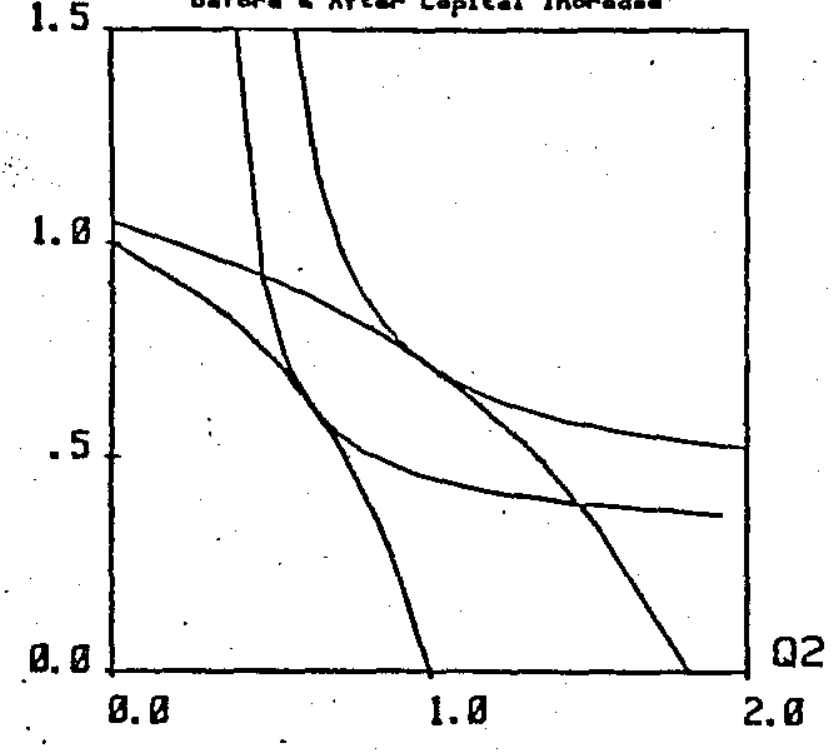

Q1 Production Isoquants

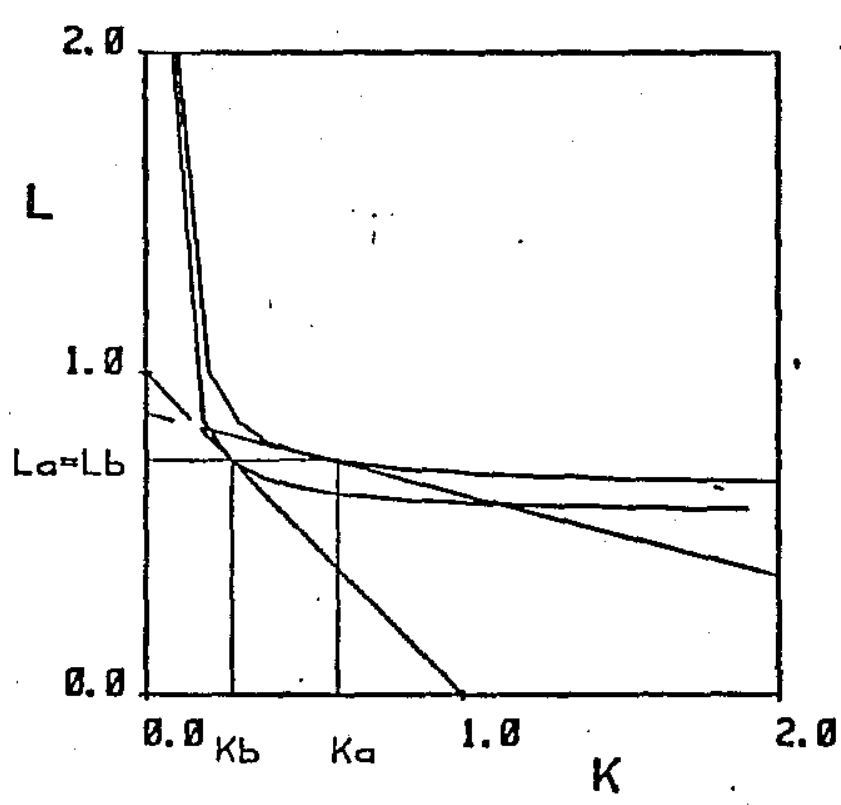

Q2 Production Isoquants

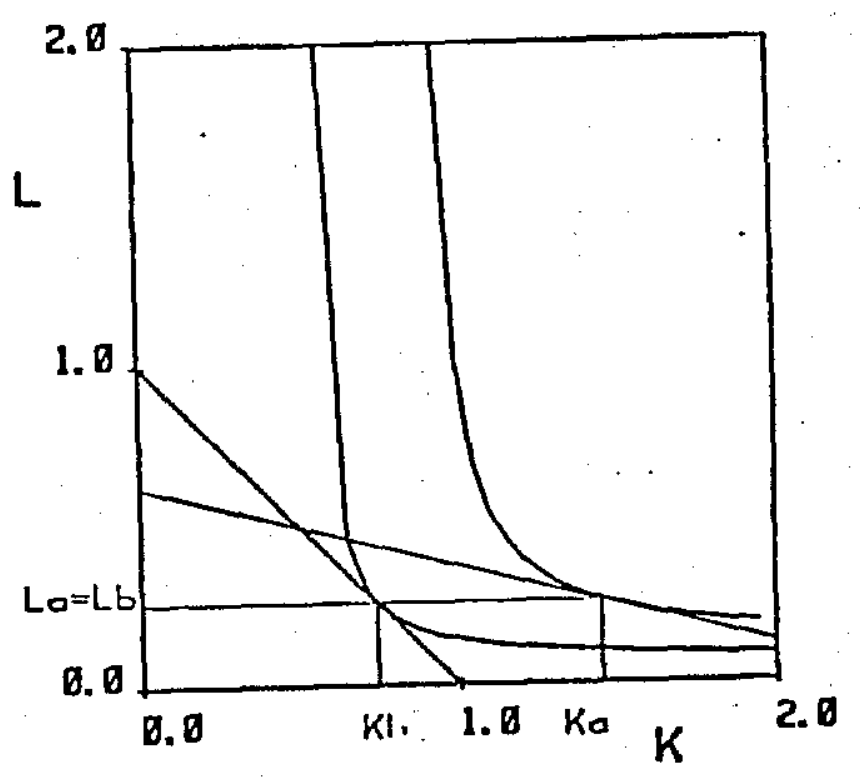

FIGURE 1: Offsetting Fxpansion and Substitution Effects

(1)

I

. 
For any general equilibrium model the sum of factor demands across all industries equals the (inelastic) aggregate factor supply, before and after a change in endowments. In other words:

$$
\left[\underset{g=1}{\mathrm{NCOM}} A^{*}(g, f) / \underset{g=1}{\mathrm{NCOM}} A(g, f)\right]=X^{*}(f) / X(f),
$$

for all f... In our special case:

$$
\stackrel{*}{A}(g, f) / A(g, f)=* *(f) / X(f),
$$

for all $f, g$ pairs. Thus, what is special about our Analytic Factor Price Solution is that the expansion effect is exactly offset by the substitution effect in each and every industry. 


\section{Section 4 \\ THE FACTOR PRICE REVISION RULE}

Useful as the Analytic Factor Price Solution may be, it does not appear to generalize to include certain important features of applied general equilibrium models. It does, however, motivate a simple and powerful iterative algorithm for use in more general problems.

The critical step in revising factor prices over iterations involves the following Factor Price Revision Rule:

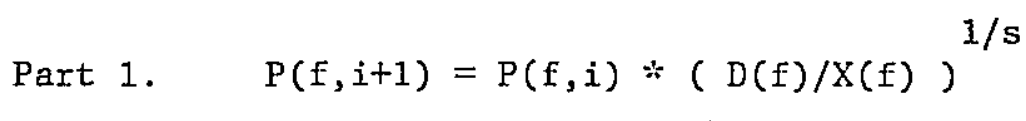

for $f=1$ to NFAC, and where $P(f, i)$ is now the price of factor $f$ at iteration $i$; and

Part 2. (Renormalize) $P(f, i+1)=P(f, i+1) / P(1, i+1)$

for $f=2$ to NFAC. The price of the first factor is taken without loss of generality to be the numeraire, and is simply re-set to unity.

Notice that the Factor Price Revision Rule is a simple Walrasian rule that raises the price of a factor in excess demand, lowers the price of a factor in excess supply, and leaves unchanged the price of a factor with own-demand equal to own-supply.

The magnitude of the price revision, for a given ratio of demand to supply, is determined by the reciprocal of the elasticity of substitution. This is a crucial discovery that critically influences the speed of convergence. If the 
elasticity of substitution is very low, say 0.10 , then the ratio of demand to supply in market $\mathrm{F}$ is raised to the tenth power in determining the price revision factor. If the elasticity of substitution is very high, say 10 , then the tenth root of the ratio of demand to supply is the price revision factor. The low elasticity revision rule causes far more "energetic" changes in factor prices than the high elasticity case (for given values of the ratio of demand to supply). 


\section{Section 5 \\ THE FACTOR PRICE REVISION RULE AS A GENERAL ALGORITHM}

We now prove that for special (but still reasonably general) cases, the Factor Price Revision Rule is equivalent to the exact closed form analytic solution to the GE model specified. This result is then used to examine the generality of the models for which the Factor Price Revision Rule provides a rapid solution technique, but for which no closed form solution is apparent.

\subsection{STRUCTURAL FORM OF THE GENERAL EQUILIBRIUM MODEL}

The structural form of the model is specified in terms of tastes, taxes, technologies and endowments. Our notation is defined in a Glossary presented in Table 1 .

Tastes are specified by a CES utility function of one consumer for NCOM goods :

$$
\mathrm{U}=\left(\underset{g=1}{\mathrm{NCON}} \mathrm{b}(\mathrm{g}) \mathrm{Q}(\mathrm{g})^{\mathrm{I}}\right)^{1 / \mathrm{r}}
$$

Taxes, $T(f, g)$, are defined as unity plus the fractional rate of taxation on the use of factor $f$ in industry (or region) $g$. Industry $g$ therefore pays $T(f, \dot{g}) \div P(f)$ for each unit of factor $f$ utilized, but the factor owner receives only $P(f)$.

Technologies are specified by CES production functions for each good $\mathrm{g}$, defined over NFAC factors: 
TABLE 1

GLOSSARY OF NOTATION

SYMBOL DEFINITION

NFAC Number of factors of production.

NCOM Number of produced goods (commodities).

$P(f, i)$ Price of factor $f$, for $f=1$ to NFAC, at iteration $i$. The iteration subscript may be dropped when there is no good pedagogic purpose to keep it.

$P(g)$. Price of produced good $g$, for $g=1$ to NCOM.

$F(f, g)$ Factor intensity -- number of units of factor $f$

$T(f, g)$ Tax rate (plus 1 ) on use of factor $f$ in industry $g$.

$\mathrm{Q}(\mathrm{g}) \quad$ Aggregate quantity of good $\mathrm{g}$ demanded by the (single) consumer.

$d(f, g)$ Distribution parameter of factor $f$ in CES production

$a(g)$ Effictioncy parameter for producing good $g$.

$b(g)$ Distribution parameter for good $\mathrm{g}$ in the utility

- function of the (single) consumer.

s Elasticity of substitution for the CES production functions of all goods and one utility function.

$r=1-(1 / \mathrm{s})$, useful transform of $\mathrm{s}$.

$X(f) \quad$ Endowment of factor $f$, in physical units.

$D(f)$ Demand for factor $f$.

E Summation symbol.

$$
Q(g)=a(g)\left(\sum_{f=1}^{N F A C} d(f, g) F(f, g)^{r}\right)^{1 / r}
$$

for $g=1$ to NCOM.

Endowments are exogenously given as $X(f)$, for $f=1$ to NFAC. Notice the implied restriction that the elasticity of substitution is uniform in technology and tastes. There is only one consumer.

Factor intensities are derived from minimizing total cost, subject to the production of unit output for each good g, yielding: 
(1)

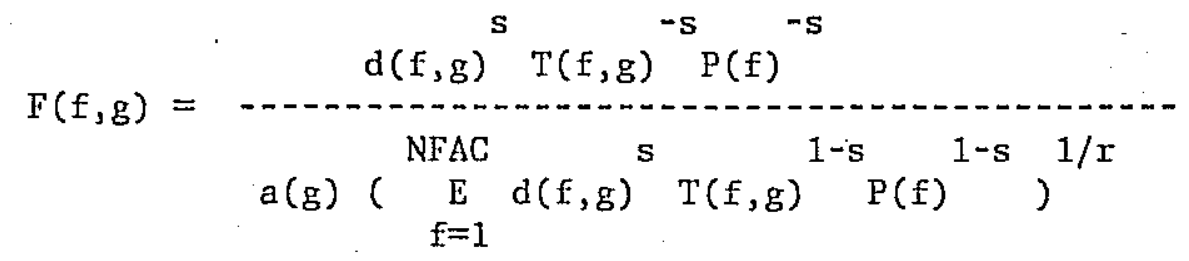

for $f=1$ to $\mathrm{NFAC}$, and $g=1$ to NCOM.

Output prices are derived analytically from the requirement that in longrun equilibrium each industry has zero profits, and from constant returns to scale, yielding:

$$
\begin{aligned}
& \text { (2a) } \quad P(g)=\underset{f=1}{N F A C} F(f, g) T(f, g) P(f), \text { for } g=1 \text { to NCON, or } \\
& \text { (2b) } \quad P(g)=(1 / a(g))\left({\underset{f=1}{E} d(f, g)^{S} T(f, g)^{1-s} P(f)^{1-s}}^{N F A C} 1 /(1-s)\right.
\end{aligned}
$$

for $g=1$ to NCOM.

Wealth (or Income) is defined as the sum of the products of endowed factors and factor prices:

$$
\text { (3) } \quad W={\underset{f=1}{\mathrm{NFAC}}}_{\mathrm{E}=1} \mathrm{P}(f) X(f) \text {. }
$$

Output demands are derived by maximizing utility subject to the budget constraint, yielding:

$$
\text { (4a) } Q(g)=\frac{W b(g)^{s} P(g)^{-s}}{\sum_{g=1}^{N C O M} b(g)^{s} P(g)^{1-s}}
$$


for $g=1$ to NCON. Substituting expression (2) for output prices into equation (4a) expresses output demands in terms of factor prices:

(4b)

$$
\begin{aligned}
& W a(g)^{s} b(g)^{s}\left(\sum_{f=1}^{N F A C} d(f, g)^{s} T(f, g)^{1-s} P(f)^{1-s}\right)^{1 / r} \\
& Q(g)=\sum_{g=1}^{N} a(g) b(g) \quad\left(\sum_{f=1}^{E} d(f, g)^{S} T(f, g)^{1-s} P(f)^{1-s}\right)
\end{aligned}
$$

for $g=1$ to NCON.

Producers are instructed to produce exactly the quantities demanded, thereby forcing demand to equal supply in all output markets. Any disequilibrium must therefore appear in factor demands. Private Factor Demands are derived by suming the products of output demands and factor intensities over all private good production. The results are:

$$
\text { (5a) } \quad D(f)=\underset{g=1}{\mathrm{NCOM}} Q(g) F(f, g)
$$

for $f=1$ to NFAC. Government factor demands are derived by exhausting tax revenue on the purchase of factors in proportion to aggregate private factor demands ${ }^{5}$. Total factor demands are then simply some scalar multiple, $c \cdot D(f)$, of private factor demands (where $c$ is greater than or equal to unity). Substituting expression (4b) for $Q(g)$, and expression (1) for $F(f, g)$ yields the expression for Total Factor Demands:

(5b) $\quad \mathrm{D}(\mathrm{f})=\mathrm{K} * \mathrm{~K}(\mathrm{f}) * \mathrm{P}(\mathrm{f})^{-\mathrm{s}}$

for $f=1$ to NFAC, and where

5 The government output is distributed free of charge as a public good. 
and

$$
K(f)={\underset{g=1}{\mathrm{NCON}} a(g)^{s-1}}^{\mathrm{N}=1(g)^{s}} d(f, g)^{s} T(f, g)^{-s}
$$

$$
\begin{aligned}
& \text { NFAC } \\
& c *[\underset{f=1}{E} X(f) P(f)] \\
& \sum_{f=1}^{N}\left({ }_{g=1}^{N} a(g) b(g)^{s} d(f, g)^{s} T(f, g)^{1-s}\right) P(f)^{1-s}
\end{aligned}
$$

It becomes important in the sequel to recognize that $K$ is the same for all factors, and that $K(f)$ is only a function of parameters (i.e., it is not a function of any endogenous variable).

\subsection{A SPECIAL CASE: THE ANALYTIC FACTOR PRICE SOLUTION}

In equilibrium the demand for each factor, $D(f)$, equals the (inelastic) factor supply, $X(f)$ :

(6) $X(f)=K * K(f) * P(f)^{-s}$

for $f=1$ to NFAC. Let factor 1 be the numeraire and find the ratios of factor demands (or supplies) for non-numeraire factors to factor 1 demand (or supply):

$$
\begin{aligned}
& \text { (7) } \quad X(f) \quad K(f) \quad P(f)^{-s} \\
& \mathrm{X}(1) \quad \mathrm{K}(1) \quad \mathrm{P}(1)
\end{aligned}
$$

for $f=2$ to NFAC. Solving (7) for $P(f)$ yields: 


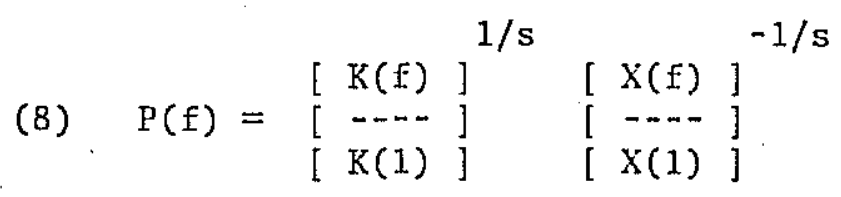

for $f=2$ to NFAC (note that $P(1)=1.00$ ), and where

$$
K(f)=\underset{g=1}{N C O M}\left(a(g)^{s-1} b(g)^{s} d(f, g)^{s} T(f, g)^{-s}\right)
$$

Equation (8) is the exact algebraic solution to the class of general equilibrium models specified. Substitution of equation (8) for $P(f)$ in equations (1) - (4) gives the complete algebraic reduced form of the mode1; that is, each endogenous variable expressed as explicit algebraic functions of exogenous variables and parameters.

Without essential loss of generality, the full reduced form of the GE model without taxes and with $a(g)=1$ for $a 11 g=1$ to NCOM is as follows. The presence of a numeraire complicates notation needlessly, but multiplying the vector of factor prices in (8) by

$$
\mathrm{K}(1)^{1 / \mathrm{s}} * \mathrm{X}(1)^{-1 / \mathrm{s}}
$$

avoids these problems. This normalization leads to the following simple form for Factor Prices:

$$
P(f)=K(f)^{1 / s} X(f)^{-1 / s},
$$

for $\dot{f}=1$ to $N F A C$, where 


$$
\begin{aligned}
& K(f)=\underset{g=1}{\mathrm{NCON}} B(g) * D(g, f), \\
& D(g, f)=d(g, f)^{s} \text { and } B(g)=b(g)^{s} .
\end{aligned}
$$

Goods prices are

$$
P(g)=\left[\underset{f=1}{E} D(g, f) K(f)^{-r} X(f)^{r}\right]^{1 /(1-s)}
$$

for $g=1$ to NCOM. Factor intensities are

$$
F(g, f)=D(g, f) K(f)^{-1} X(f) \quad[\underbrace{N F A C}_{f=1} D(g, f) K(f)^{-r} X(f)^{r}]^{-1 / r}
$$

for $\stackrel{E=1}{=1}$ to NFAC and $g=1$ to NCOM. Wealth is

$$
W=\underset{f=1}{\operatorname{NFAC}} K(f)^{1 / s} X(f)^{r}
$$

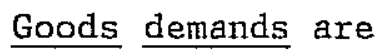

$$
Q(g)=B(g)\left[\underset{f=1}{\mathrm{NFAC}} D(g, f)^{\prime} K(f)^{-r} X(f)^{r}\right]^{1 / r},
$$

for $g=1$ to NCOM, and Factor demands are trivially $D(f)=X(f)$ for $f=1$ to NFAC. An Appendix (available on request) provides a simple computationally recursive statement of the complete GE solution.

The reason our Factor Price Revision Rule worked in one iteration for these models can now be shown. The Rule, restated with iteration subscripts explicitly included now, is: 


$$
\begin{array}{ll}
\text { Part 1. } & P(f, i+1)=P(f, i)(D(f) / X(f))^{1 / s} \\
& \text { for } f=1 \text { to NFAC. } \\
\text { Part 2. } & P(f, i+1)=P(f, i+1) / P(1) \\
& \text { for } f=2 \text { to NFAC, and } \\
& P(1, i+1)=1.00 .
\end{array}
$$

Substitute expression (5b) for $D(f)$ into Part 1 , yielding:

$$
P(f, i+1)=P(f, i):\left[\begin{array}{c}
{\left[K * K(f) *(P(f, i))^{-s}\right]} \\
{[0]}
\end{array}\right]^{1 / s}
$$

for $f=1$ to NFAC. This reduces to:

$$
P(f, i+1)=K^{1 / s} K(f)^{1 / s} X(f)^{-1 / s}
$$

for $f=1$ to NFAC. Normalization, in Part 2, then gives:

$$
P(f, i+1)=(K(f) / K(1))^{1 / s}(X(f) / X(1))^{-1 / s}
$$

for $f=2$ to NFAC. This, of course, is expression (8) for the exact analytic solution. In other words, after one iteration factor prices are identically equal to the values they would have been had we used the exact solution in the first place ${ }^{7}$.

7 It is worth observing that if we had not been simulating models numerically it is virtually inconceivable that we would have been motivated to prove that such a remarkably simple result was the solution to arbitrarily large general equilibrium models. This is not the first time serendipity has played a role in deductive science: 


\subsection{FOUR IMPORTANT EXTENSIONS}

It would be nice if a closed-form solution could be found for GE models of arbitrary functional form and specification. As noted earlier, our Analytic Factor Price Solution does not appear to generalize to include several features of contemporary, policy-oriented, numerical GE models. This subsection demonstrates the apparent bounds on the existence of such closed-form solutions. On a more positive note, however, we attempt to explain why our iterative Factor Price Revision Rule works so well for more general models that incorporate these "realistic" extensions.

\subsubsection{Multiple Consumers}

A derivation similar to the above can proceed in the case of multiple consumers with varying tastes and endowments to the point of an expression for factor demands (analogous to (5b) above). Let the distribution parameters in tastes be indexed by consumer $\mathrm{n}$ (for NHHD consumers) as well as good $\mathrm{g}$, $B(n, g)$, and let household $n$ endowments of factor $f$ be denoted $X(n, f)$. Reverting to the no-tax case, factor demands then become:

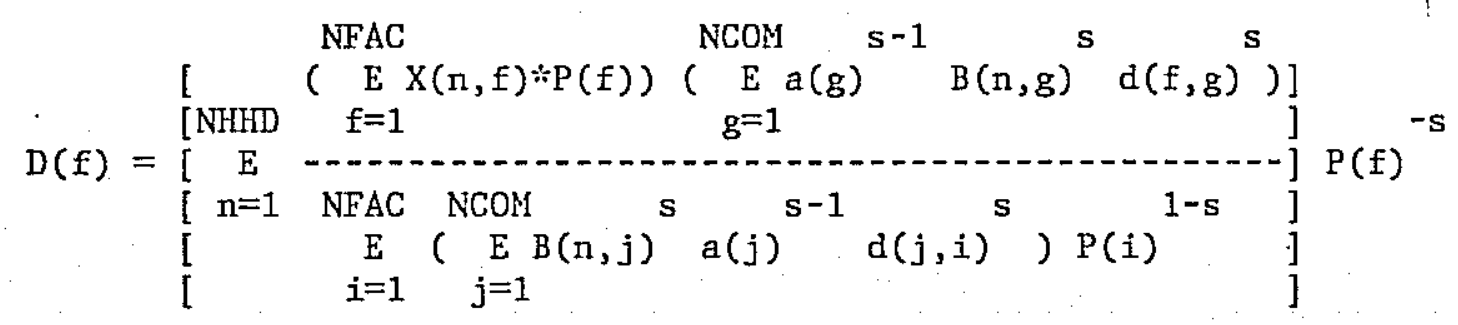

for $f=I$ to NFAC.

With only one consumer the large bracketed expression can be factored into the product $K * K(f)$ where $K$ is a function of factor prices but is not specific to factor $\underline{f}$, and where $K(f)$ is specific to factor $f$ but is not a function of 
factor prices. Taking the ratio $D(f) / D(1)$ then eliminates $K$, so a closed form solution emerges.

No apparent simplification is available when there are multiple consumers who are differentiated by tastes and/or endowment distribution. The K(f) term, which is an interaction between tastes and production function parameters, is weighted by the wealth of households -- but these depend on factor prices. This appears to prevent a closed form solution.

However, unless there are strong interactions among endowments, taste parameters and production function distribution parameters, the bracketed term does not vary across factors very much. An initial, possibly crude, guess at factor prices is apparently sufficient to let the typically stronger relative endowment term

$$
(X(E) / X(1))^{-1 / s}
$$

estimate relative factor prices fairly closely. This argument rationalizes the fact that our Factor Price Revision Rule has worked well as an iterative solution algorithm in spite of not giving the exact solution to more general cases.

\subsubsection{Non-Uniform Elasticities of Substitution}

In the case where elasticities of substitution in production differ from the elasticity of substitution in tastes, a derivation similar to the closed form analytic solution can proceed to equation (5b), except that the $K(f)$ factor becomes

$$
K(f)={\underset{g=1}{N C O M}}_{g(g)}^{s-1} b(g)^{u-1} d(f, g)^{s} T(f, g)^{-s} P(g)^{s-u},
$$


where $\mathbf{s}$ is the elasticity of substitution 'in each sector's production function, $u$ is the elasticity of 'substitution in the utility function, and $P(g)$ is the price of output in industry $g$. The $K(f)$ factor was previously a function of parameters only; here it is a function of endogenous variables and no closed form solution is apparent.

Notice that as the elasticities approach each other, the last term,

$$
P(g)^{s-u}
$$

approaches unity and the Analytic Factor Price Solution emerges. Notice also that if output prices are unity (as they might be in the "base case") then this term also disappears. Therefore, in practice, if elasticities do not vary too much or if relative goods prices are close to unity, this term may be relatively small and the Factor Price Revision Rule can give very rapid convergence even though the Rule omits this term.

\subsubsection{Intermediate Trade}

A common specification of production in applied GE models is that the production function for each good is Leontief with respect to all inputs (intermediate and final), but that the primary factor is a composite input produced with a C.E.S. technology. The efficient choice of primary inputs is therefore trivially separable from the use of intermediate inputs. If we define $F 2(f, g)$ as the embodied (direct plus indirect) factor intensity of $f$ in the production of $g$ (i.e., the number of units of factor $f$ needed directly and indirectly to produce one unit of good $g$ ), we may employ one of the fundamental relations of Input-Output analysis to define 


$$
\text { (1') } \quad F 2(f, g)=\sum_{k=1}^{N C O N} F(f, j) * L(k, g)
$$

for $f=1$ to NFAC, $g=1$ to NCOM, and where $L$ is the standard Leontief Inverse. In matrix notation, $I$ is given as

$$
L=(I-A)^{-1}
$$

where. I is an NCOM-by-NCOM identity matrix and $A$ is the non-negative matrix of direct intermediate requirements (i.e., each column of A shows the direct physical requirements of each row sector output per unit output of the column sector). If we assume that $I$ exists and is non-negative then we may write it as the following useful matrix expansion:

$$
L=I+A+A^{2}+A^{3}+\ldots
$$

We may further define

$$
C=I-I=A+A^{2}+A^{3}+\ldots
$$

allowing us to re-state $\left(1^{\prime}\right)$ as

$$
\left(1{ }^{\prime \prime}\right) \quad F 2(f, g)=F(f, g)+\sum_{k=1}^{N C O M} F(f, k) * C(k, g)
$$

for $f=1$ to NFAC, and $g=1$ to NCOM.

The original derivation strategy may now proceed with intermediate trade by substituting $F 2(f, g)$ at appropriate places for $F(f, g)$. Expression (5a) becomes: 


$$
\left(5 a^{\prime}\right) \quad D(f)={\underset{g}{E=1}}_{E}^{N C O M} Q(g) * F(f, g)+\underset{g=1}{E} Q(g) *[\underset{k=1}{N} F(f, k) * C(k, g)] .
$$

The first expression in (5a') represents "direct" derived demand for factor $f$, and the second expression represents "indirect" derived demand for factor $f$. With no intermediate trade the $C$ matrix is null, (5a') reduces immediately to (5a) and the Analytic Factor Price Solution emerges as before. When $\mathrm{C}$ is nonnu11, however, no apparent simplification of (5a') to "isolate" $P(f)$ is possible.

\subsubsection{The Role of Government}

The Analytic Factor Price permits completely general specifications of ad valorem factor taxes, which are used commonly in applied general equilibrium taxation analysis to approximate corporate profits taxes, social security taxes, and other tax structures ${ }^{8}$. The expenditure side of fiscal incidence, however, poses a problem for an exact analytic solution. In the special case where the exact algebraic solution holds we assumed that government demands factors in the same proportion as the aggregate of private industry demands. This assumption permits the demand for factors (demanded by private industries and government) to be stated solely as a function of private industry demands.

Assuming that government demands factors based on some rule other than that they be proportional to aggregate private demands (e.g., cost minimization with a balanced budget) leads to an expression for factor demands similar to (5b), except that there is an additional term reflecting government demands. The formal problem for an exact solution lies in the fact that government re-

8 See Fullerton, Shoven, and Whalley [1981] for an exhaustive GE characterization of the United States taxation system. 
venues from ad valorem factor taxes depend on factor prices, inter alia, but factor prices depend, in turn, on government factor demands. This prevents as apparent exact closed-form solution. However, if government demands are relatively small, and/or roughly similar to the demands by the private sector, then an initial rough guess at factor prices will permit very rapid iterations towards the solution since government demands are very much second-order adjustments to the solution obtained by ignoring the difference between private industry demands and total demands.

Our assumption about government factor demands has the same force as assumptions used originally by Harberger to "neutralize" the role of government. Commenting on a presentation of the Analytic Factor Solution in Kimbell and Harrison [1983], McLure [1983] notes a similarity between the requirement that we have a single consumer (discussed above) and this assumption on government factor demands:

It is interesting to note that these limitations on the analytical solution are closely related to those found in the early Harberger literature and force similar simplifying assumptions. In his original article, Harberger was concerned solely with what Musgrave has called incidence on the side of sources of income, that is, with effects on relative factor prices. To simplify analysis he assumed that at the margin redistribution of income within the private sector made no difference for aggregate consumption patterns, by giving everyone the same marginal expenditure pattern. Since he was not concerned with effects on relative product prices and changes in the distribution of income resulting from such changes, he was not concerned that there would be no redistributional effect on the side of uses of income if average private spending patterns were also identical. Wheareas Harberger sacrificed examination on the uses side of income in order to simplify his analysis, Kimbell and Harrison are forced to make the same sacrifice in order to obtain an exact ana1ytical solution using their Factor Price Revision Rule. Whereas the uses side could be salvaged in the earlier analysis by assuming (usually implicitly) a non-unitary income elasticity of demand, Kimbell and Harrison can achieve the same result by using the powerful computational algorithn based on their Factor Price Revision Rule, rather than relying on an analytical solution.

If marginal and public spending patterns diverge, the existence of government keeps the authors from having, in effect, a one-con- 
sumer mode1. But for the analysis of tax incidence it would be quite satisfactory to assume identical marginal public and private expenditure patterns, especially if incidence on the uses side is already being i.gnored by lumping all consumers together. 


\section{Section 6}

\section{ILLUSTRATIVE APPLICATIONS}

\subsection{SOME FAMILIAR ANALYTIC RESULTS}

\subsubsection{Tax Incidence Analysis}

It is possible to analytically derive several standard results from the Tax Incidence literature with our Analytic Factor Price Solution, accepting the assumptions noted above for the existence of the closed-form solution. To simplify notation let

$$
h(f, g)=a(g)^{s-1} b(g)^{s} d(f, g)^{s},
$$

and

$$
M=K(1)^{-1 / s}(X(f) / X(1))^{-1 / s} .
$$

Factor prices then become:

(9) $\quad P(f)=\left(\sum_{g=1}^{\mathrm{NCOM}} h(f, g) T(f, g)^{-5}\right)^{1 / s} * M$

for $f=2$ to NFAC and with $P(1)=1$. A standard Harberger-Mieszkowski-McLure result emerges from expression (9): if the tax expressions $T(f, g)$ are increased in proportion $V$ for all uses of factor $f$ (e.g., the property tax is increased in all regions) then factor price $f$ changes by exactly the reciprocal of $V$. This result obtains by substituting $V * T(f, g)$ into expression (9) and factoring out $1 / V$. Capitalists bear fully a uniform nation-wide increase in property taxes. 
There are no excise tax effects in this case. 'The expression for product prices obtained from the zero-profit condition becomes with taxes:

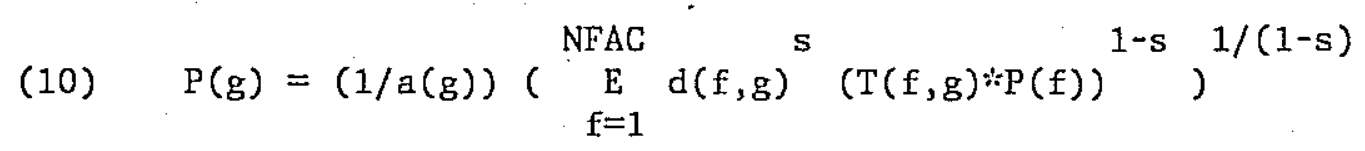

for $g=1$ to NCOM. Replace $P(f)$ in the expression for product prices by $T(f, g) * P(f)$ to obtain equation (10). But increasing $T(f, g)$ by $V$, for a1l $f$, leads to $P(f) / V$, so the products $(T(f, g) \div V)(P(f) / V)=T(f, g) \div P(f)$, and all product prices are invariant to the uniform-across-factor-uses tax increase.

Increasing the tax on one use of factor $f$ is not the same, of course, as increasing taxes on all uses. In the original Harberger [1962] context the corporate profits tax was treated as levied on the use of capital in one sector, and in the Mieszkowski-McLure work on regional tax incidence an increase in property tax on one region is recognized as fundamentally different from a uniform nation-wide tax change.

For expository convenience let $h(f, g)=1.00$ in expression (9), for all pairs $g$ and $f$. In the base case let $T(f, g)=1.00$, again for $a 11 \mathrm{~g}$ and $f^{9}$. As the alternative, let the tax on the use of factor $f$ in industry (or region) $g$ increase by $V(f, g)$. The ratio of factor price $f$ after the tax increase, $P(f)^{\prime}$, to the price before the tax change; $P(f)$, becomes:

$$
\begin{aligned}
& P(f)^{\prime} \\
& -P(f)
\end{aligned}=\left[\begin{array}{cc}
G-1 & 1
\end{array}\right] 1 / s
$$

This means that no taxes are levied in the base case. 
where $G$ is the number of equally sized industries (or regions). It is obvious that as $G$ grows larger the price of factor $E$ is less and less affected (although it is always lower after the tax increase). The returns to a mobile factor are not significantly affected by a change in taxes on its usage in one sma11 industry (or region).

These familiar tax incidence results illustrate the potential analytical uses of the closed form solution without any necessary numerical calculations.

\subsubsection{International Trade Theory}

International trade theorists have refined our knowledge of the properties of neoclassical GE models; see Jones [1965], Kemp [1969], and Jones and Schienkman [1977], for example. Jones and Schienkman [1977; p.911] note that the

standard Heckscher-Ohlin model of international trade incorporates a set of propositions that reveal essential properties of the two-commodity, two-factor general equilibrium model of production., of these propositions, four are central:

i) The Heckscher-Ohlin Theorem links the pattern of trade to factor intensities and factor endowments. A country exports that commodity that uses intensively the factor that is relatively cheap prior to trade.

ii) The Factor-Price Equalization Theorem suggests that freetrading commodities is sufficient to cause factor prices to be equal between countries even if factor supplies cannot cross national boundaries.

iii) The Stolper-Samuelson Theorem states that an increase in the price of some commodity (through tariff policy, e.g.) must unambiguously raise the real reward to some factor of production.

iv) The Rybczynski Theorem points out that if prices are kept constant but the endowment of some factor rises, not all outputs can expand. The production of some commodity must fall.

It is convenient to group (i) and (ii) and (iii) and (iv) together. [... The] essence of propositions (i) and (ii) is the link between factor and commodity prices in any particular country. 
A direct mapping from factor prices to commodity prices exists for the GE model presented in Section 5.1 (see the Appendix):

$$
P(g)=\left[\sum_{f=1}^{N F A C} D(g, f) P(f)^{1-s}\right]^{1 /(1-s)}
$$

for $g=1$ to NCOM. With a transformation of variables we have the following simple matrix mapping ${ }^{10}$ :

$$
\begin{aligned}
& \mathrm{Z}=\mathrm{D} \quad * \quad \mathrm{~V} \\
& (\text { NCOM } \times 1) \quad(\text { NCOM } \times \text { NFAC }) \quad(N F A C \times 1) \\
& \text { where } Z(g)=P(g)^{1-s} \quad \text { for } g=1 \text { to NCOM, and } \\
& V(f)=P(f)^{1-s} \quad \text { for } f=1 \text { to NFAC. }
\end{aligned}
$$

If the (arbitrary) number of commodities equals the number of factors (i.e., NCOM $=(N F A C)^{11}$, and the matrix $D$ is non-singular, the following inverse mapping from commodity prices to factor prices also exists:

$$
\mathrm{V}=\mathrm{D}^{-1} \quad * \quad \mathrm{Z}
$$

$(\operatorname{NFAC} \times 1) \quad($ NFAC $\times$ NCOM $) \quad($ NCOM $\times 1)$

Thus

$$
P(f)=\left[\underset{g=1}{E} \operatorname{NCON} D 2(g, f) P(g)^{1-s}\right]^{1 /(1-s)}
$$

10 The dimensions of each matrix are presented in brackets underneath the corresponding variable.

11 Note that the previous mapping does not require this equality. 
for $f=1$ to NFAC, and where $D 2$ is the inverse of $D$. Proof of the Factor-Price Equalization Theorem is quite elegant using this mapping ${ }^{12}$. Partition the price vectors of both goods and factors into two halves, referring to two countries:

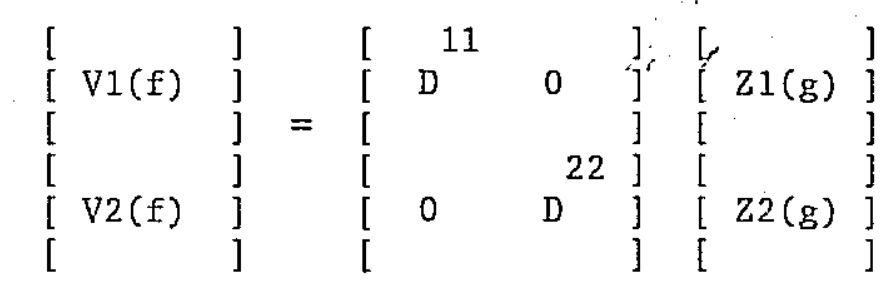

Trade in commodities makes the vector $\mathrm{P} 1(\mathrm{~g})=\mathrm{P} 2(\mathrm{~g})$, so the vector $\mathrm{Z} 1(\mathrm{~g})=$ $\mathrm{Z} 2(\mathrm{~g})$. Assuming identical technologies means

$$
D^{11}=D^{22},
$$

so the vector $V 1(f)=V 2(f)$. Hence factor prices are equalized; $i . e$, the vector $P 1(f)=P 2(f)$. These, of course, are the basic mappings emphasized above by Jones and Schienkman. Several novel features of these mappings should be noted:

i) they refer to global and exact GE solutions, rather than local and approximate solutions;

ii) with appropriate partitioning of commodities and factors, one may simultaneously obtain comparative static propositions for all relevant regions or nations, rather than for a single region or nation ${ }^{23}$,

12 For all prices of country-specific goods to exist requires that all countries produce all goods, ruling out specialization problems.

13 Kimbell and Harrison [1983; Section 3.2] demonstrate the analytic and empirical nature of this general partitioning procedure. The Heckscher-Ohlin assumption of inter-sectorally mobile factors that are inter-regionally immobile is a special case of that procedure, which allows for quite general configurations of factor specificity and mobility. 
and

iii) it is a GE solution, and not a Partial Equilibrium solution taking commodity prices as given (the "small open economy" assumption of given world prices).

There also exists a simple GE linear mapping, felevant to the Rybczynski Theorem, from physical factor endowments to the output of goods. One remarkable property of our analytic solution in this case is that every. endogenous variable can be similarly transformed and represented as a linear matrix mapping of physical endowments (also transformed). Further study of these important mappings is beyond the scope of the present paper, but provides a strengthening and generalization of received trade theory in the sense noted above.

\subsection{SOME COMPUTATIONAL EXPERIENCE}

Table 2 illustrates the speed of convergence to a GE set of twelve relative factor prices in a hypothetical model developed in Kimbe11 and Harrison [1983; Section 4.1]. The model deviated in several respects from the class for which the Analytic Factor Price Solution applies: multiple consumer types were allowed, and government factor demands were not proportional to aggregate factor demands. Four goods are produced, and there are thirteen factors ${ }^{14}$. The measure of convergence used is the absolute value of the maximum factor market disequilibria expressed as a percentage of the aggregate endowment of that factor ${ }^{15}$.

14 Further details of the model may be found in Kimbell and Harrison [1983], and are not relevant here.

15 Convergence was assumed when this criterion was less than 0.100 . 
The first run shown corresponds to the use of the unit vector as an initial guess at the equilibrium factor prices; in this case the Factor Price Revision Rule was able to solve the basic model in nine iterations. The second run adopts starting values for factor prices that are deliberately disturbed inignificantly" away from the (known) equilibrium solution. The sizeable (maximum percent) disequilibrium of 1423.977 (see iteration 1 for Run 2 in Table 2) indicates what our algorithm had to overcome (relative to Run 1). A new solution was found in nine iterations. Indeed, after the shock of the first iteration the Rule tended to follow the convergence path of Run 1 .

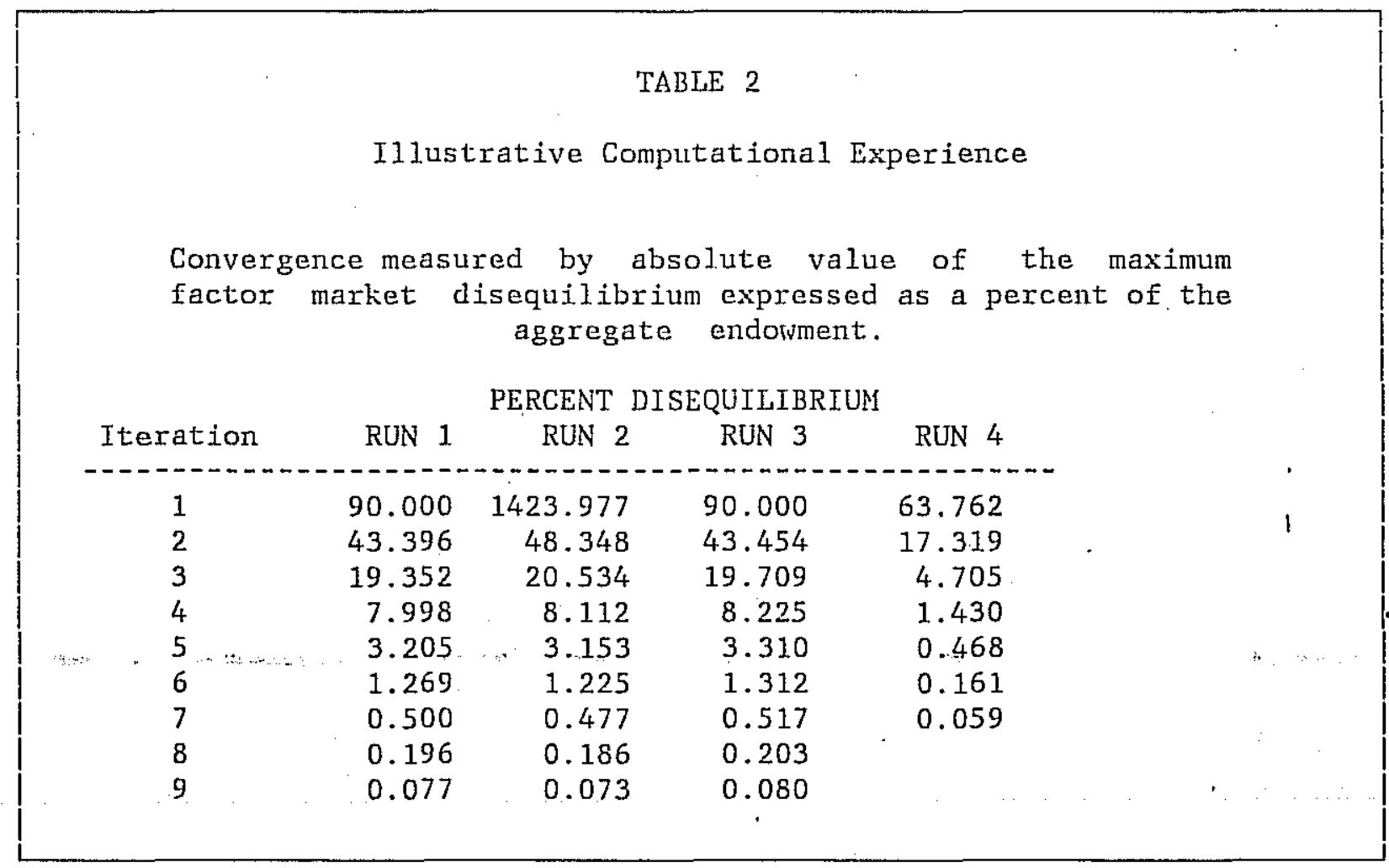

The third run adopts the unit vector of factor prices as. a starting point, but unlike Run 1 assumes that intermediate trade is allowed between commodi- 
ties. The Leontief Inverse used for this exercise was pseudo-randomly generated $^{15}$. The convergence path again parallels that observed in Run 1 , with a solution (quite different from the solution found in Run 1 or Run 2) rapidly found.

The fourth run shown in Table 2 illustrates a common situation $-\cdots$ given the general equilibrium solution found ín Run 1 (or Run 2), we search for a new solution after some policy perturbation. In this case we increase the tax on one (fully mobile) factor's use in the production of one good from $5 \%$ to $100 \%$. The Factor Price Revision Rule is able to return us to a general equilibrium with a mere seven iterations.

Another illustration of the speed of our solution procedures is provided earlier by Figure 1. To trace out Production Possibility Curves such as those illustrated there requires (at least) forty complete GE solutions; in the present case the Analytic Factor Price Solution was able to generate this frontier about as rapidly as it could be plotted. Despite the precision of purely numerical solutions to GE models, the traditional international trade and tax incidence literature has powerfully demonstrated the insights possible from heuristic constructs such as those presented in Figure 1. Our computational procedures permit a synthesis of these alternative, and complementary, representations of GE solutions.

16 With the restriction that off-diagonal elements take values between 0.3 and 0.5 , and diagonal elements take values between one and 1.500 . Run 1 essentially assumes that this is an identity matrix. 


\section{Section 7 \\ CONCLUDING PERSPECTIVES}

This paper has developed two broad solution procedures for popular GE models, integrating closed-form and iterative methods. These procedures enlarge the set of techniques available to GE analysts interested in deriving theoretical propositions, empirical propositions, or both. Moreover, analysts can readily develop large-scale numerical counterparts to GE models with known closed-form solutions, allowing a tighter link between theoretical and empirical results.

Another major application of our procedures is in the detailed study of the properties of large-scale GE models of recent vintage. The early numerical (or computable) GE models of Scarf [1967] [1973] were modest in size (e.g., two or three producing sectors and two or three primary factors), qualitative 1y "general" (in the sense of imposing very weak regularity conditions on model structure), and calibrated with hypothetical data. Shoven and Whalley [1972], Shoven [1976] and Whalley [1977] provided the first small, qualitatively "restrictive", policy-relevant GE models. Familiar functional forms were chosen for utility and production functions (e.g., single-level CES), techniques for empirical calibration (viz., the notion of a "benchmark equilibrium") were developed, and policy issues familiar from the Harberger [1962] literature re-examined. More recent developments have extended this class to include "reasonably large" models with twenty or more producing sectors and/or four or more primary factors. Variations on the popular functional forms have also been adopted (e.g., multi-level CES, and LES demand systems), and a wide 
range of policy issues considered. Fullerton,' Henderson and Shoven [1983], Kimbell and Harrison [1983], and Sicarf and Shoven [1983] provide surveys of these developments ${ }^{17}$.

The policy-relevance of these models, and their avowedly "empirical" na ture, render them open to casual criticism. Most economists are deeply familiar with their underlying neoclaśsićal structure; we are not therefore concerned to defend them from criticisms based on rejection of that structure on the othex hand, criticism based on suspicion of the particular empirical calibration adopted currently :leads to non-systematic and/or uninformed debate. The general techniques used to calibrate numerical GE models are discussed in the references given above, and elsewhere ${ }^{18}$. Given, then, that users of numerical GE models are increasingly "informed" as to the various sources of data embodied in their simulations, how is one to systematically identify the robustness of the results for some particular decision? Our response to this important question is to urge a systematic sensitivity analysis of the base case policy simulations. A number of critical dimensions to such analysis may be readily identified from any discussion of the procedures used to calibrate GE modelsig. The solution methods developed in the present paper are $\underset{1}{\mathrm{~b}}$.

17 Our remarks pertain directly to the class of models mentioned above. A variant on this class is the so-called "Johansen-like" model -- see Dixon, Parmenter, Sutton, and Vincent [1981] for a review. The general thrust of our remarks below also apply to these numerical GE models.

18 See Mansur and Whalley [1983], Fullerton, Henderson and Shoven [1983], StHillaire and Whalley [1980], Piggott and Whalley [1983], and Fullerton, Shoven and Whalley [1983].

19 For one obvious example, consider the elasticities of substitution in production used to calibrate the CES production functions of each sector. Popular calibration procedure is to employ a vector of point estimates based on a search of the available econometric literature. Assuming that such a vector is available, such estimates are of course accompanied by standard errors. The vector of estimates formed by considering all combinations of estimates within one standard error (say) of the point estimate for each 
cope with the severe computational burden of sensitivity analysis of complete GE models.

sector provides a continuum of distinctly calibrated GE models whose comparative static (policy) properties need not be identical. Piggott and Whalley [1983; ch.4/6] provide a complete exposition. of. these calibration procedures: 


\section{Appendix A}

\section{A SIMPLE RECUURIVE SOLUTION}

In Section 5.2 we presented the complete reduced form solution of a particular GE structural mode $1^{20}$ In this section we present a recursive (from "top-tobottom") version of the same solution, which is much more attractive computationaliy.

Recalling the additional notation of Section 5.2 (especially the definitions of $D(g, f)$ and $B(g))$, Factor prices are given by

$$
P(f)=K(f)^{1 / 5} X(f)^{-1 / 5}
$$

for $f=1$ to NFAC. Goods prices are then given by

$$
P(g)=\left[\underset{f=1}{\mathrm{NFAC}} D(g, f) P(f)^{1-s}\right]^{1 /(1-s)}
$$

for $g=1$ to NCOM. Factor intensities are then given by

$$
F(g, f)=D(g, f) *[P(g) / P(f)]^{s}
$$

for $f=1$ to NFAC and $g=1$ to NCOM. Wealth is then

20 In addition to the assumptions necessary for the Analytic Factor Solution, we assume for notational ease that $a(g)=1$ for $a 11 \cdot g=1 \cdot$ to NCOM and that there are no factor taxes. 


$$
W=\underset{f=1}{\mathrm{NFAC}} P(\mathrm{f}) X(\mathrm{f})
$$

Goods demands are then given for $g=1$ to NCON by

$$
\begin{aligned}
& W B(g) P(g)^{-s} \quad \because{ }^{\prime} \\
& \mathrm{Q}(\mathrm{g})=\frac{\mathrm{NCON}}{1-\mathrm{S}}=\mathrm{B}(\mathrm{g}) \mathrm{P}(\mathrm{g})^{-\mathrm{s}}, \\
& \text { E } B(g) \quad P(g) \\
& g=1 \text {. } \\
& \text { since } W=\underset{g=1}{\mathrm{NCOH}} B(g) P(g)^{1-s} \text {. }
\end{aligned}
$$

Factor allocations are given as

$$
F 3(g, f)=F(g, f) * Q(g)=D(g, f) B(g) P(f)^{-s}
$$

for $\mathrm{f}=1$ to NFAC and $\mathrm{g}=1$ to NCOM. Factor demands are given as

$$
D(f)=\underset{g=1}{\mathrm{NCOH}} F 3(g, f)=\underset{g=1}{\mathrm{NCOM}} F(g, f) * Q(g)=X(f)
$$

for $f=1$ to NFAC. Factor shares, $S(g, f)$, the fraction of $X(f)$ allocated to Q(g) production, are

$$
S(g, f)=A(g, f) / X(f)=D(g, f) B(g)[K(f) / K(1)]^{1 / s}
$$

for $f=1$ to NFAC and $g=1$ to NCOM. 


\section{BIBLIOGRAPHY}

Dixon, P.B.; Parmenter, B.R.; Sutton; J.; and Vincent, D.P., ORANI: A Multisectoral Model of the Australian Economy, (North-Holland Publishing Co., Amsterdam, 1981):

Fullerton, D.; Henderson, Y.K.; and Shoven, J.B., "A Comparison of Methodologies in Empirical General Equilibrium Models of Taxation", in H.E. Scarf and J.B. Shoven (eds.), Applied General Equilibrium Analysis, (University of Chicago Press, Chicago, 1983).

Fullerton, D.; King, A.; Shoven, J.B.; and Whalley, J., "Corporate Tax Integration in the United States: A General Equilibrium Approach", American Economic Review, v. 71, 1981, p. 677/691.

Fullerton, D., Shoven, J.B., and Whalley, J., "General Equilibrium Analysis of U.S. Taxation Policy", in 1978 Compendium of Tax Research (Office of Tax Analysis, U.S. Department of the Treasury, Washington D.C., 1978).

Harberger, A.C., "The Incidence of the Corporate Income Tax", Journal of Political Economy, v. 70, 1962, p. 215/240.

Harberger, A.C., and Bruce, N., "The Incidence and Efficiency Effects of Taxes o: Income from Capital: A Reply", Journal of Political Economy, v. 84, 1976, p. 1285/1292.

Jones, R.W.; "The Structure of Simple General Equilibrium Models", Journal of Political Economy, v. 72, 1965, p.557/572.

Jones, R.W., and Schienkman, J.A., "The Relevance of the Two-Sector Production Model of Trade Theory", Journal of Political Economy, v. 85, 1977, p. $909 / 935$.

Kemp, M.C., The Pure Theory of International Trade and Investment (PrenticeHall, Englewood Cliffs, 1969).

Kimbell, L.J., and Harrison, G.W., "General Equilibrium Analysis of Regional Fiscal Incidence", in H.E. Scarf and J.B. Shoven (eds.), Applied General Equilibrium Analysis (University of Chicago Press, Chicago, 1983).

Mansur, A., and Whalley, J., "Numerical Specification of Applied General Equilibrium Models: Estimation, Calibration, and Data", in H.E. Scarf and J.B. Shoven (eds.), Applied General Equilibrium Analysis (University. of Chicago Press, Chicago, 1983).

McLure, C.E.Jr., "General Equilibrium Incidence Analysis: The Harberger Model After Ten Years", Journal of Public Economics, v. 4, 1975, p. 125/161. 
McLure, C.E.Jr., "Comments on 'General Equilibrium Analysis of Regional Fiscal Incidence'", in H.E. Scarf and J.B. Shoven (eds.), Applied General Equilibrium Analysis (University of Chicago Press, Chicago, 1983).

Piggott, J.R., and Whalley, J., Economic Effects of U.K. Tax-Subsidy Policies: A General Equilibrium Appraisal, (Macmillan, New York, 1983).

Scarf, H., "On the Computation of Equilibrium Prices", in Ten Economic Essays in the Tradition of Irving Fisher (Wiley, New York, 1967).

Scarf, H., in collaboration with $\ddot{T}$. Hansen, The Computation of Economic Equilibria (Yale University Press, New Haven, 1973).

Scarf, H.E., and Shoven, J.B. (eds.), Applied General Equilibrium Analysis (University of Chicago Press, Chicago, 1983).

Shoven, J.B., "The Incidence and Efficiency Effects of Taxes on Income from Capital", Journal of Political Economy, v. 84, 1976, p.1261/1283.

Shoven, J.B., and Whalley, J., "A General Equilibrium Calculation of the Effects of Differential Taxation of Income from Capital in the U.S.", Journal of Public Economics, v. 1, 1972, p. 281/321.

St-Hillaire, F., and Whalley, J., "A Microconsistent Equilibrium Data Set for Canada for Use in Tax Policy Analysis", Working Paper, University of Western Ontario, Department of Economics, December 1980.

Wha1ley, J., "The United Kingdom Tax System 1968-1970: Some Fixed Point Indications of Its Economic Impact", Econometrica, v. 45, 1977, p. $1837 / 1858$. 